DAMBIT, T.F. et al. Impactos do uso da somatotropina bovina recombinante (rbST) sobre a reprodução de ruminantes. PUBVET, Londrina, V. 8, N. 19, Ed. 268, Art. 1787, Outubro, 2014.

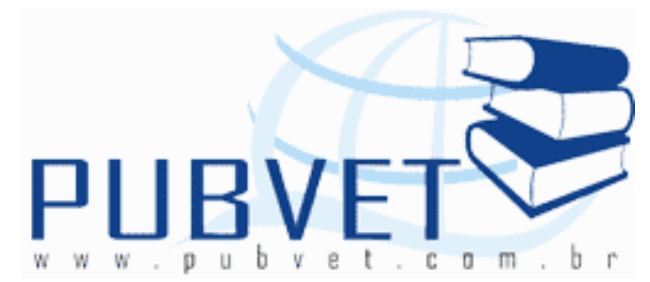

PUBVET, Publicações em Medicina Veterinária e Zootecnia.

\title{
Impactos do uso da somatotropina bovina recombinante (rbST) sobre a reprodução de ruminantes*
}

Tamiris Franke Dambit ${ }^{1}$, Valéria Caobianco Sant'ana ${ }^{2}$, Robson Oliveira dos Santos ${ }^{1}$, Márcio Augusto Ferreira ${ }^{2}$, Paulo César Varoni ${ }^{3}$

${ }^{1}$ Medico(a) veterinário(a) autônomo(a).

2 Professor(a) doutor(a) da Universidade Guarulhos

${ }^{3}$ Professor da Universidade Guarulhos

* Trabalho de Conclusão do Curso de Medicina Veterinária da Universidade Guarulhos, da primeira autora sob orientação da segunda autora.

\section{Resumo}

A somatotropina recombinante bovina (rbST) tem sido apontada como uma substância que pode auxiliar nas tecnologias da reprodução de ruminantes, entretanto, poucos estudos sobre sua utilização nesta área, tanto em pequenos como em grandes ruminantes, têm sido publicados, talvez devido à sua proibição em alguns países. Conhecida também como hormônio do crescimento, a somatotropina quando utilizada, faz com que o organismo desenvolva reações, na maioria das vezes favoráveis, no que se diz respeito em melhorar características reprodutivas, tais como taxa de concepção, maturação in vitro de oócitos, cultivo in vitro de embriões, entre outras, entretanto, para que seja possível uma melhor compreensão do uso da rbST 
DAMBIT, T.F. et al. Impactos do uso da somatotropina bovina recombinante (rbST) sobre a reprodução de ruminantes. PUBVET, Londrina, V. 8, N. 19, Ed. 268, Art. 1787, Outubro, 2014.

sobre algumas ferramentas utilizadas na reprodução são necessários que mais estudos sejam realizados para completa compreensão de suas ações. 0 principal objetivo do presente trabalho é mostrar, através de uma revisão bibliográfica, os possíveis efeitos da rbST nas tecnologias da reprodução de ruminantes.

Palavras-chave: Somatotropina Recombinante Bovina; Hormônio do crescimento; Reprodução; Ruminantes.

\title{
Impact of the use of Recombinant Bovine Somatotropin (rbST) on the reproduction of ruminants
}

\begin{abstract}
Recombinant Bovine Somatotropin (rbST) has been identified as a substance that can positively impact the reproduction of ruminants, there are, however, few studies published of its use in this area, perhaps because rbST has been banned in many countries. Also known as growth hormone, somatotropin causes favorable reactions related to improving reproductive characteristic such as conception rate, in vitro maturation of oocytes, in vitro embryo culture among others. More studies are needed in order to better understand the effects of rbST and its possible use as a tool to improve the reproduction of ruminants. This article is a review of the literature on the possible effects of rbST in the reproduction of ruminants.
\end{abstract}

Keywords: Recombinant Bovine Somatotropin; Growth hormone; Reproduction; Ruminants. 
DAMBIT, T.F. et al. Impactos do uso da somatotropina bovina recombinante (rbST) sobre a reprodução de ruminantes. PUBVET, Londrina, V. 8, N. 19, Ed. 268, Art. 1787, Outubro, 2014.

\section{INTRODUÇÃO}

A somatotropina recombinante bovina (rbST) é uma variante sintética do hormônio hipofisário natural conhecido como hormônio do crescimento (GH) ou somatotropina bovina (bST). A bST apresenta estrutura primária diferente do hormônio do crescimento humano e por isso não apresenta atividade biológica nesta espécie (Breton et al., 2009). Sua ação ocorre mediante ligação aos receptores de membrana específicos e, portanto, não tem efeito em humanos, já que os receptores são bastante diferentes. Por ser uma estrutura protéica, é degradada por peptídeos no trato digestivo ao serem ingeridos por via oral e seguro em relação à saúde humana (Li et al., 1945; Bauman e Vernon, 2007).

Os efeitos da bST sobre a lactação e o crescimento são conhecidos desde as décadas de 20 e 30 do século passado, porém grande número de pesquisas passaram a ser realizadas após o desenvolvimento da tecnologia de DNA recombinante que proporcionou o desenvolvimento do rbST com o mesmo potencial biológico e permitiu a produção do hormônio em escala ( $\mathrm{Li}$ et al., 1945). A grande maioria desses estudos foi realizada para detalhar a ação do hormônio sobre a produção de leite em vacas e, em menor número, os trabalhos tratam dos efeitos em pequenos ruminantes, em outros tecidos, ganho de peso e na saúde dos animais como um todo.

Nos últimos anos, boa parte dos estudos realizados com a rbST apresentam direcionamento sobre os efeitos na esfera reprodutiva, especialmente aliada às biotecnologias. Neste sentido, este trabalho visa agregar os conhecimentos desenvolvidos sobre a aplicação de tratamentos com rbST nas características reprodutivas de ruminantes. 
DAMBIT, T.F. et al. Impactos do uso da somatotropina bovina recombinante (rbST) sobre a reprodução de ruminantes. PUBVET, Londrina, V. 8, N. 19, Ed. 268, Art. 1787, Outubro, 2014.

\section{MECANISMOS DE AÇÃO}

A somatotropina é um hormônio pituitário que controla diversos aspectos do crescimento corporal e metabolismo de nutrientes no animal, além destas características a somatotropina (ST) influencia as funções reprodutivas (Etherton et al., 1998). A secreção pela adenohipófise é estimulada pelo hormônio liberador de somatotrofina e inibida pela somatostatina, ambos produzidos pelo hipotálamo (Kolb, 1984).

A ação direta da ST na reprodução é evidente devido a presença de mRNA (RNA mensageiro) para receptores deste hormônio em diversos tipos celulares do sistema reprodutivo. Já foram descritas a presença de mRNA para receptores de ST em células do hipotálamo, hipófise, corpo lúteo, folículos ovarianos, ovidutos, endométrio e placenta (Gong et al., 1991; Lucy et al., 1998). O fígado é o tecido que apresenta a maior expressão dos receptores de ST, quando estimulado por este hormônio responde realizando a síntese e secreção do fator de crescimento semelhante à insulina I (IGF-I) e sua proteína carreadora -IGFPB (Jones et al., 1995). Assim, foi postulado que a ação da ST no crescimento e na reprodução seja mediada pelo IGF-I produzido pelo fígado (Giudice, 1992; Spicer et al., 1995). A figura 1 demonstra o mecanismo para a ação da ST e sua molécula mediadora IGF-1. 
DAMBIT, T.F. et al. Impactos do uso da somatotropina bovina recombinante (rbST) sobre a reprodução de ruminantes. PUBVET, Londrina, V. 8, N. 19, Ed. 268, Art. 1787, Outubro, 2014.

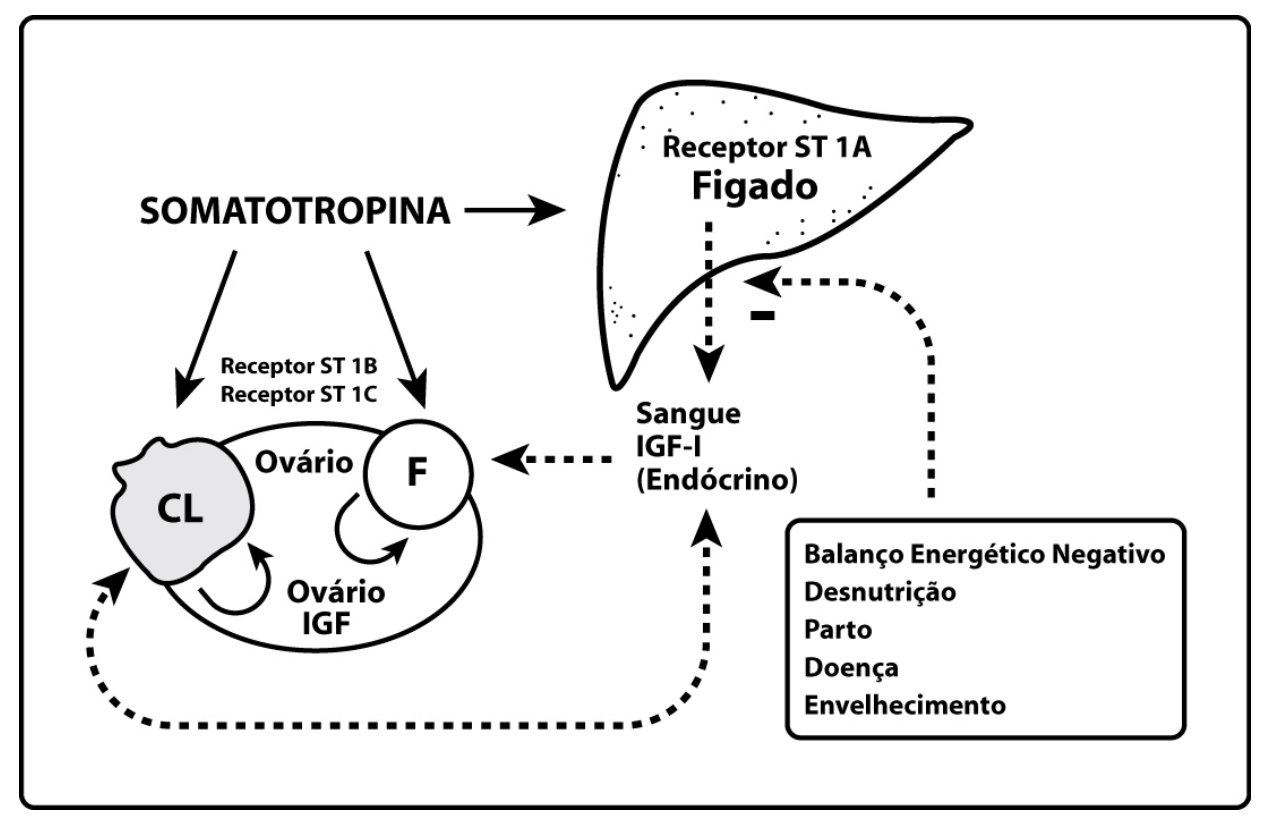

Figura 1 - Figura esquemática da ação da somatotropina em tecidos do ovário. Fonte: Adaptado de Lucy (2000)

\section{PARÂMETROS REPRODUTIVOS}

Estudando os efeitos da ST em parâmetros reprodutivos Dohoo et al., (2003) realizaram uma meta-análise com a produção científica da última década. Com este estudo puderam observar os efeitos da ST em parâmetros reprodutivos em diversas categorias de animais e diferentes protocolos de aplicação da rbST. Os principais resultados encontrados na literatura referente aos efeitos da rbST sobre a reprodução de ruminantes estão descritos nos tópicos que seguem e no quadro 1. 
DAMBIT, T.F. et al. Impactos do uso da somatotropina bovina recombinante (rbST) sobre a reprodução de ruminantes. PUBVET, Londrina, V. 8, N. 19, Ed. 268, Art. 1787, Outubro, 2014.

Quadro 1 - Efeitos da rbST sobre índices reprodutivos em ruminantes.

\begin{tabular}{|c|c|c|}
\hline $\begin{array}{l}\text { Parâmetros } \\
\text { reprodutivos }\end{array}$ & Resultados & Autor (es) \\
\hline $\begin{array}{c}\text { Taxa de } \\
\text { serviço/concepção }\end{array}$ & $\begin{array}{l}\text { Não sofreu influência } \\
\text { significativa. }\end{array}$ & $\begin{array}{c}\text { Franson et al., 1989; } \\
\text { Pell et al., } 1992 .\end{array}$ \\
\hline \multirow[t]{2}{*}{ Taxa de concepção } & $\begin{array}{c}\text { Influência positiva: } \\
\text { maiores taxas de } \\
\text { concepção. }\end{array}$ & $\begin{array}{l}\text { Moreira et al., 2001; } \\
\text { Morales-Roura et al., } \\
\text { 2001; } \\
\text { Santos et al., 2004; } \\
\text { Melanie et al., } 2006 .\end{array}$ \\
\hline & $\begin{array}{l}\text { Redução da } \\
\text { mortalidade } \\
\text { embrionária. }\end{array}$ & Santos et al., 2004. \\
\hline $\begin{array}{l}\text { Intervalo entre } \\
\text { parto/concepção }\end{array}$ & $\begin{array}{l}\text { Aumento significativo } \\
\text { de } 5 \text { dias no intervalo } \\
\text { parto/concepção. }\end{array}$ & Dohoo et al., 2003. \\
\hline \multirow{2}{*}{ Gestação gemelar } & $\begin{array}{c}\text { Não sofreu influência } \\
\text { significativa. }\end{array}$ & Collier et al., 1996. \\
\hline & $\begin{array}{l}\text { Grande aumento no } \\
\text { risco de gestação } \\
\text { gemelar. }\end{array}$ & Bauman et al., 1987. \\
\hline $\begin{array}{c}\text { Incidência de cistos } \\
\text { ovarianos }\end{array}$ & $\begin{array}{l}\text { Não sofreu influência } \\
\text { significativa. }\end{array}$ & $\begin{array}{l}\text { Bauman et al., 1987; } \\
\text { Franson et al., } 1989 .\end{array}$ \\
\hline
\end{tabular}


DAMBIT, T.F. et al. Impactos do uso da somatotropina bovina recombinante (rbST) sobre a reprodução de ruminantes. PUBVET, Londrina, V. 8, N. 19, Ed. 268, Art. 1787, Outubro, 2014.

\subsection{Taxa de serviço/concepção}

O número de serviços por concepção, isto é, o número de inseminações que uma vaca necessita para atingir a concepção não sofreu influência significativa com rbST em rebanhos comerciais (Franson et al., 1989; Pell et al., 1992). Este dado reflete que o uso rbST não altera a condição reprodutiva a ponto de suprir problemas de manejo nutricional ou de puerpério. Sendo o manejo, fundamental para viabilizar a utilização da rbST como estratégia farmacológica para a melhoria reprodutiva.

\subsection{Taxa de concepção}

A taxa de concepção sofre influência positiva com 0 uso de tratamentos com rbST. Melanie et al. (2006) reportaram taxa muito superior de concepção em vacas lactantes $(n=48)$ tratadas com dose única de rbST, $60 \%$ para o grupo tratado e $40 \%$ para o grupo controle. Da mesma forma, Santos et al. (2004) aplicaram 500 mg de rbST a cada 14 dias em 840 vacas com 60 dias pós-parto e observaram maiores taxas de concepção em vacas tratadas. Puderam observar também redução de aproximadamente $60 \%$ na mortalidade embrionária nestes animais.

Os efeitos da rbST também tem demonstrado bons resultados na taxa de concepção em protocolos de inseminação artificial em tempo fixo (IATF). Moreira et al. (2001) observaram que animais tratados com rbST durante protocolos hormonais para IATF obtiveram taxa superior de concepção ao primeiro serviço em comparação ao grupo controle. Os resultados encontrados sugerem que o efeito benéfico da administração da rbST ocorra no período da ovulação até 32 dias após a inseminação.

A aplicação da rbST foi testada por Morales-Roura et al. (2001) em vacas repetidoras de cio na tentativa de utilizar este hormônio para tratar problemas de fertilidade. Obtiveram taxa de concepção significativamente 
DAMBIT, T.F. et al. Impactos do uso da somatotropina bovina recombinante (rbST) sobre a reprodução de ruminantes. PUBVET, Londrina, V. 8, N. 19, Ed. 268, Art. 1787, Outubro, 2014.

superior nos animais tratados $(29,3 \%)$ quando comparados aos animais controle $(16,9 \%)$.

\subsection{Intervalo entre parto/concepção}

O intervalo entre parto/concepção ou período de serviço é o número de dias que um animal necessita para recuperar seu escore corporal e realizar a involução uterina para uma nova gestação. Este índice sofre influência de diversas condições de manejo nutricional e complicações do puerpério. No estudo retrospectivo de Dohoo et al. (2003) foi identificado aumento significativo de 5 dias no intervalo parto/concepção em vacas tratadas com rbST. No entanto, da mesma maneira que a taxa de serviço/concepção, a influência de fatores ambientais e de manejo exercem maior impacto nestes índices do que a utilização de tratamentos exógenos. É conveniente avaliar que animais tratados com rbST apresentam maior produção leiteira, por isso devem receber melhores condições nutricionais para a manutenção de sua saúde reprodutiva.

\subsection{Gestação gemelar}

A maioria das evidências a favor do aumento no risco de gestação gemelar provém do estudo de Collier et al. (1996). Os resultados desse trabalho são contraditórios já que a diminuição no risco em vacas primíparas e aumentado risco em vacas multíparas não tenha sido significativo. Outro estudo relatou grande aumento no risco de gestação gemelar associado a rbST, índices de risco de 7,1 e 11,7 em vacas primíparas e multíparas, respectivamente (Bauman et al., 1987). No entanto, deve notar-se que nesse estudo a via de administração utilizada foi intramuscular. Outro problema com a avaliação do impacto da rbST sobre a gestação gemelar foi o número limitado de estudos em que as vacas foram acompanhadas até o parto. Embora os dois estudos principais que fornecem dados sobre o risco de gestação gemelar totalizaram 791 vacas, uma análise correta exigiria 
DAMBIT, T.F. et al. Impactos do uso da somatotropina bovina recombinante (rbST) sobre a reprodução de ruminantes. PUBVET, Londrina, V. 8, N. 19, Ed. 268, Art. 1787, Outubro, 2014.

dados de 2.000 vacas aproximadamente divididas em dois grupos (Dohoo et al., 2003). De qualquer maneira, mesmo que o número de animais avaliados seja insuficiente para análise robusta de variância, o uso da rbST provoca um aumento no risco de gestação gemelar. Isso demonstra uma ação pró-ativa no número de ovulações a cada ciclo estral.

\subsection{Incidência de cistos ovarianos}

Embora Collier et al. (1996) tenham observado aumento no risco de cistos ovarianos em vacas tratadas com rbST, na maioria dos trabalhos pesquisados o risco da ocorrência da condição de cisto ovariano não foi significativo (Franson et al., 1989; Bauman et al., 1987). Tais observações levaram Dohoo et al. (2003) a concluírem que a aplicação da rbST aumenta a atividade ovariana em vacas, sem causar aumento significativo na incidência de cistos ovarianos.

\section{TRANSFERÊNCIA DE EMBRIÕES (TE)}

Existem várias restrições para a implementação de biotecnologias da reprodução na pecuária. Dentre elas a mais relevante é a incapacidade de alcançar elevada resposta superovulatória constante (Hasler, 1998; Thatcher et al., 2001). Uma explicação para a inconsistência dos rendimentos de embriões após a superovulação é o pequeno número de folículos ou crescimento folicular insuficiente. Tratamentos que aumentem o número de folículos e seu crescimento, por conseguinte, podem melhorar a superovulação. Neste sentido, a rbST pode ser utilizada para melhorar a resposta superovulatória.

Outra possibilidade para o uso de rbST na indústria de transferência de embriões está nas receptoras. A administração de rbST em animais submetidos a inseminação artificial (Moreira et al., 2000), ou antes da transferência do embrião (Moreira et al., 2001) aumenta da taxa de 
DAMBIT, T.F. et al. Impactos do uso da somatotropina bovina recombinante (rbST) sobre a reprodução de ruminantes. PUBVET, Londrina, V. 8, N. 19, Ed. 268, Art. 1787, Outubro, 2014.

concepção. Assim, a rbST pode gerar alterações positivas no útero favorecendo o desenvolvimento do embrião.

Os resultados encontrados na literatura, que seguem descritos nos tópicos abaixo, podem ser melhor visualizados no quadro 2 .

Quadro 2 - Efeitos da somatotropina bovina sobre a resposta superovulatória, tamanho folicular e número de prenhezes.

\begin{tabular}{|l|l|l|}
\hline Grupo tratado & Resposta & Autor(es) \\
\hline \multirow{2}{*}{ Doadoras } & $\begin{array}{l}\text { Melhor resposta } \\
\text { superovulatória com } \\
\text { maior crescimento } \\
\text { folicular. }\end{array}$ & Cushman et al., 1999. \\
\cline { 2 - 3 } & $\begin{array}{l}\text { Tamanho folicular } \\
\text { médio maior. }\end{array}$ & Bols et al., 1998. \\
\hline \multirow{2}{*}{ Receptoras } & $\begin{array}{l}\text { Aumento não } \\
\text { significativo no número } \\
\text { de prenhezes }\end{array}$ & Hasler et al., 2003. \\
\hline
\end{tabular}

\subsection{Doadoras}

A utilização da rbST em protocolos de superovulação foram testados em diferentes sistemas de criação e apresentam resultados variáveis entre os trabalhos. Cushman et al. (1999) demonstraram melhor resposta superovulatória em bovinos com maior crescimento folicular. Bols et al. (1998), realizando sessões consecutivas de superovulação, demonstraram que a partir da décima aspiração, animais do grupo tratado com rbST apresentavam tamanho folicular médio $13 \%$ maior do que no grupo controle. Entre a $1^{\text {a }}$ e a 12 a sessão, o número total de folículos atingiu um patamar $22 \%$ maior para o grupo tratado com rbST. 
DAMBIT, T.F. et al. Impactos do uso da somatotropina bovina recombinante (rbST) sobre a reprodução de ruminantes. PUBVET, Londrina, V. 8, N. 19, Ed. 268, Art. 1787, Outubro, 2014.

Em ovelhas, Castro et al (2002) não observaram aumento na taxa de ovulação, outros pesquisadores, porém, afirmam que o aumento no recrutamento folicular promovido pela rbST favorece a resposta aos tratamentos superovulatórios e se traduz por um maior número de folículos disponíveis à ação das gonadotrofinas exógenas e maior tendência à obtenção de ovócitos de boa qualidade (Pivato, 2005). Em ovelhas Santa Inês, Silva et al (2010) apesar de não observarem diferença estatística entre os animais tratados com rbST no dia cinco do protocolo de superovulação, os resultados de número médio de embriões ( $G T=13,67 ; G C=11,70)$, média de embriões por animal ( $\mathrm{GT}=4,22 ; \mathrm{GC}=3,30$ ) e taxa de conversão média ( $\mathrm{GT}=58,39 \% ; \mathrm{GC}=44,26 \%$ ) favoreceram os animais do grupo tratado (GT) em relação ao controle (GC).

A atividade positiva da rbST também pode ser observada nos estudos de Gong et al. (1993), em que foi possível um número significativamente maior de estruturas recuperadas em animais tratados com rbST $(23,2$ estruturas no grupo tratado contra 12,5 no grupo controle).

O número de folículos antrais nos ovários aumenta após o tratamento com rbST. Herrier et al. (1994) observaram que no dia da inseminação artificial (IA), o dobro de folículos com mais que $4 \mathrm{~mm}$ foram contados nos animais tratados com rbST. Em um segundo experimento, observaram que no dia 7 após a IA houve mais embriões transferíveis no grupo rbST $(4,2)$ em relação ao grupo controle $(2,5)$.

$\mathrm{O}$ pré-tratamento com rbST aumentou significativamente o número de ovulações $(p<0.01)$, o total no número de oócitos/embriões recuperados e número de embriões transferíveis (Gong et al., 1996). Maior viabilidade dos embriões quando tranferidos resultou de vacas tratadas com rbST. Uma taxa de $56,1 \%$ de prenhez foi alcançada com uso de embriões congelados provenientes de doadoras tratadas e quando utilizados embriões de doadoras não tratadas esta taxa ficou em $25,1 \%$ (Thatcher et al., 2001). 
DAMBIT, T.F. et al. Impactos do uso da somatotropina bovina recombinante (rbST) sobre a reprodução de ruminantes. PUBVET, Londrina, V. 8, N. 19, Ed. 268, Art. 1787, Outubro, 2014.

Doadoras tratadas com rbST no dia 11 e no dia 4 do protocolo de superovulação apresentaram aumento no número de corpos lúteos em relação ao controle e significante aumento na porcentagem de embriões transferíveis (Kuehner et al., 1993).

\subsection{Receptoras}

O tratamento de receptoras com rbST imediatamente após a inovulação dos embriões foi testada em 146 vacas Angus (Hasler et al., 2003). Foi observado um aumento porém não significativo no número de prenhezes nos animais tratados com rbST e inovulados com embriões produzidos in vivo. Enquanto Moreira et al. (2001) concluíram que ocorra efeito benéfico da administração da rbST no período da ovulação até 32 dias após a inseminação. Com base nestes resultados podemos inferir uma ação direta ou mediada por IGF-I no sistema reprodutivo feminino que auxilia a reconhecimento materno fetal e a placentação embrionária.

Os efeitos positivos do uso da rbST na taxa de concepção pode estar não só no trato reprodutivo da fêmea bovina, mas também no embrião e suas membranas fetais.

\section{PRODUÇÃO IN VITRO DE EMBRIÕES}

Animais são tratados por longos períodos, mais que dois meses, com rbST para aumentar a produção leiteira em rebanhos comerciais, isso pode causar grandes impactos na performance reprodutiva, um exemplo é o desenvolvimento aumentado do folículo dominante (Jimenez-Krassel et al., 1999). Estas observações sugeriram a aplicação da rbST nos protocolos de produção in vitro de embriões. A rbST pode ser adicionada aos meios de maturação in vitro de oócitos ou utilizados nos meios de cultivo in vitro de embriões, os resultados obtidos em ambas situações estão descritas nos itens que seguem (Quadro 3). 
DAMBIT, T.F. et al. Impactos do uso da somatotropina bovina recombinante (rbST) sobre a reprodução de ruminantes. PUBVET, Londrina, V. 8, N. 19, Ed. 268, Art. 1787, Outubro, 2014.

Quadro 3 - Efeitos da somatotropina bovina sobre a produção in vitro de embriões.

\begin{tabular}{|c|c|c|}
\hline PIVE & Resultado observado & Autor(es) \\
\hline $\begin{array}{c}\text { Maturação in vitro de } \\
\text { oócitos }\end{array}$ & $\begin{array}{c}\text { Adição da rbST aos meios } \\
\text { de maturação melhoram a } \\
\text { competência de } \\
\text { desenvolvimento de } \\
\text { embriões produzidos in } \\
\text { vitro. }\end{array}$ & Tatjana et al., 2007. \\
\hline \multirow{2}{*}{$\begin{array}{c}\text { Cultivo in vitro de } \\
\text { embriões }\end{array}$} & $\begin{array}{c}\text { Aumento na produção de } \\
\text { estrógenos no cultivo in } \\
\text { vitro de células da } \\
\text { granulosa obtidas de } \\
\text { folículos de primeira onda }\end{array}$ & Jimenez-Krassel et al., \\
\hline
\end{tabular}

Nota: PIVE - Produção in vitro de embriões

\subsection{Maturação in vitro de oócitos}

Os efeitos da rbST foram avaliados na maturação nuclear e citoplasmática de oócitos bovinos maturados in vitro. É de grande importância para a este tipo de tecnologia que o processo de maturação seja otimizado, deste modo, o rendimento do número de embriões transferíveis seja melhorado.

Aos meios de maturação foram adicionados $10 \mathrm{ng} / \mathrm{ml}$ de rbST e não foram observadas alterações na porcentagem de oócitos em metáfase II (processo de maturação), no entanto, o número de blastocistos foi significativamente maior nos grupos tratados. Os embriões provenientes de oócitos maturados in vitro na presença da rbST, apresentaram melhor função mitocondrial e diminuição do cálcio intra-celular (sinal de viabilidade celular). 
DAMBIT, T.F. et al. Impactos do uso da somatotropina bovina recombinante (rbST) sobre a reprodução de ruminantes. PUBVET, Londrina, V. 8, N. 19, Ed. 268, Art. 1787, Outubro, 2014.

Os resultados encontrados neste trabalho suportam a hipótese de que a adição da rbST aos meios de maturação melhoram a competência de desenvolvimento de embriões produzidos in vitro (Tatjana et al., 2007).

\subsection{Cultivo in vitro de embriões}

O cultivo comercial de embriões bovinos, no Brasil, é realizado em condições de co-cultivo, onde os embriões são cultivados juntamente com células da granulosa. Esta metodologia é realizada devido ao cultivo conjunto trazer benefícios para os embriões, células da granulosa secretam fatores de crescimento e hormônios no meio que irão implementar a qualidade do desenvolvimento embrionário (Ménézo et al., 2010). Neste sentido, JimenezKrassel et al. (2002) avaliaram os efeitos da adição da rbST aos meios de cultivo de células da granulosa quantificando a produção de estrógenos totais produzidos por estas células. Puderam observar que a adição da rbST causa um aumento na produção de estrógenos no cultivo in vitro de células da granulosa obtidas de folículos de primeira onda, sugerindo benefício do uso da rbST em condições de cultivo in vitro.

\section{CONCLUSÕES}

Observa-se uma redução no número de artigos publicados com estudos da utilização da rbST sobre as características reprodutivas no período de 2000 a 2011. Este fato se deve provavelmente a proibição do uso deste hormônio na produção leiteira na comunidade européia. Nos últimos anos, os estudos enfocaram a deteç̧ão deste hormônio e seus resíduos no leite, a rotulagem de produtos derivados de animais tratados com rbST (Breton et al., 2010; Munro et al., 2010). Os artigos mais recentes também visam a expressão de genes envolvidos com o metabolismo da rbST (Rhoads et al., 2011). 
DAMBIT, T.F. et al. Impactos do uso da somatotropina bovina recombinante (rbST) sobre a reprodução de ruminantes. PUBVET, Londrina, V. 8, N. 19, Ed. 268, Art. 1787, Outubro, 2014.

Na reprodução de bovinos, o uso da rbST parece ser uma ferramenta que auxilia no sucesso do emprego de biotecnologias. As pesquisas sobre o efeito da rbST na reprodução assistida em pequenos ruminantes é escassa e os resultados da aplicação são inconclusivos, o que decorre da ausência de unificação de protocolos, particularidades da espécie e variabilidade no manejo nutricional. As aplicações da rbST no processo reprodutivo de bovinos é bastante promissora e necessita de maiores esforços para sua compreensão. Estudos com delineamento e quantidade satisfatórios ainda não foram desenvolvidos em rebanhos tropicais.

No Brasil, existem oportunidades promissoras para o desenvolvimento de estudos que aperfeiçoem o uso das biotecnologias já que a venda de sêmen praticamente dobrou nos últimos 10 anos (Asbia, 2010) e o país tem ocupado posição de destaque na produção de embriões com notável progresso nos últimos anos (Neves et al., 2010; Varago et al., 2008) viabilizando o desenvolvimento de novas tecnologias. As pesquisas e os debates devem ser estimulados em todas as instâncias para que o conhecimento seja ampliado e ações possam ser adotadas com segurança.

\section{REFERÊNCIAS}

ASBIA. Associação Brasileira de Inseminação Artificia, Relatório 2010l. www.asbia.com.br.

BAUMAN, D.E.; HUBER, J.T.; LAMB, R.C.; SAMUELS, W.A. Multi-location intramuscular single dose study (single dose IM) (\#85-039, \#85-038, \#85-021, \#86-003). Monsanto Study Report. St. Louis, Missouri, USA, 1987.

BAUMAN, D.E.; VERNON, R.G. Effects os exogenous bovine somatotropin on lactation. Journal Dairy Science, v.90, p. 5439-5445, 2007.

CASTRO, A.A.P.; NORO, M.; CECIM, M. A. somatotrotopina bovina recombiante sobre a ovulação, condição corporal e níveis séricos de colesterol e glicose em ovinos. Ciência Rural, v.32, n.3, p.479-483, 2002.

COLLIER, R.J. Post-approval evaluation of Prosilac bovine somatotropin in commercial dairy herds (\#93-051). Monsanto Study Report. St. Louis, Missouri, USA, 1996. 
CUSHMAN, R.A.; DESOUZA, J.C.; HEDGPETH, V.S.; BRITT, J.H. Superovulatory response of one ovary is related to the micro- and macroscopic population of follicles in the contralateral ovary of the cow. Biology of Reproduction, v. 60. p. 349-54, 1999.

DOHOO, I.R.; LESLIE, K.; DESCÔTEAUX, L.; FREDEEN, A.; DOWLING, P.; PRESTON, A.; SHEWFELT, W. A meta-analysis review of the effects of recombinant bovine somatotropin 1 . Methodology and effects on production, The Canadian Journal of Veterinary Research, v. 67 , p. 241-251, 2003.

ETHERTON, T. D.; BAUMAN, D. E. Biology of somatotropin in growth and lactation of domestic animals. Physiology Reviews, v.78, p.745-761, 1998.

FRANSON, S.E.; COLE, W.J.; MADSEN, K.S.; et al. Response of cows throughout lactation to Sometribove in a prolonged system - a dose titration study conducted at four U.S. sites (\#87-023, \#87-034, \#87-029, \#87-024). Monsanto Study Report. St. Louis, Missouri, USA.1989.

GIUDICE, L. C. Insulin-like growth factors and ovarian follicular development. Endocrine Reviews, v.13, p. 641-669, 1992.

GONG, J. G.; BRAMLEY, T. A.; WEBB, R. The effect of recombinant bovine somatotropin on ovarian function in heifers: follicular populations and peripheral hormones. Biology of Reproduction, v. 45, p. 941-949, 1991.

GONG, J.G.; BRAMLEY, T.A.; WILMUT, I.; WEBB, R. Effect of recombinant bovine somatotropin on the superovulatory response to pregnant mare blood gonadotropin in heifers. Biology of Reproduction, v. 48, p. 114-119, 1993.

GONG, J.G.; WILMUT, I.; BRAMLEY, T.A.; WEBB, R. Pretreatment with recombinant bovine somatotropin enhances the superovulatory response to FSH in heifers. Theriogenology, v.45, p.611-622, 1996.

HASLER, J.F. The current status of oocyte recovery, in vitro embryo production, and embryo transfer in domestic animals with emphasis on the bovine. Journal of Animal Science, v.76, p. 52-74, 1998.

JONES, J. I.; CLEMMONS, D. R. Insulin-like growth factors and their binding proteins: biological actions. Endocrine Reviews, v.16, p.3-33. 73, 1995.

KOLB, E. Fisiologia veterinária. 4ed. Editora Guanabara: Rio de Janeiro. 1984, 611p.

KUEHNER, L.F.; RIEGER, D.; WALTON, J.S.; ZHAO, X.; JOHNSON, W.H. The effect of a depot injection of recombinant bovine somatotropin on follicular development and embryo yield in superovulated Holstein heifers. Theriogenology; v.40, p.1003-13, 1993.

LI, C.H.; EVANS, H.M.; SIMPSON, M.E. Isolation and properties of the anterior hypophyseal growth hormone. Journal biological chemistry, p. 353-366, 1945. Disponível em www.jbc.org. Acesso em 9 set 2009.

LUCY, M. C., BOYD, C. K.; KOENIGSFELD, A. T.; OKAMURA, C. S. Expression of somatotropin receptor messenger ribonucleic acid in bovine tissues. Journal of Dairy Science, v. 81, p.1889-1895, 1998. 
MELANIE, J.; STARBUCK, E.; INSKEEP, K., DAILEY, R.A. Effect of a single growth hormone (rbST) treatment at breeding on conception rates and pregnancy retention in dairy and beef cattle. Animal Reproduction Science v. 93, p. 349-359, 2006.

MORALES-ROURA, J.S.; ZARCO, L.; HERNANDEZ-CERON, J.; RODRIGUEZ, G. Effect of shortterm treatment with bovine somatotropin at estrus on conception rate and luteal function of repeat-breeading dairy cows. Theriogenology, v. 55, P. 1831-841, 2001.

MOREIRA, F.; BADINGA, L.; BURNLEY, C.; THATCHER, W.W. [abstract], Effects of bovine somatotropin on embryo transfer in lactating dairy cows. Theriogenology, v. 55, p.367, 2001.

MOREIRA, F.; RISCO, C.A.; PIRES, M.F.A.; AMBROSE, J.D.; DROST, M.; THATCHER, W.W. Use of bovine somatotropin in lactating dairy cows receiving timed artißcial insemination. Journal of Dairy Science, v. 83, p. 1237- 47, 2000.

MOREIRA, F..; ORLANDI, C.; RISCO, C. A.; MATTOS, R.; LOPES, F.; THATCHER, W. W. Effects of presynchronization and bovine somatotropin on pregnancy rates to a timed artificial insemination protocol in lactating dairy cows. Journal of Dairy Science, v. 84, p.1646-1659, 2001.

MUNRO, J.L.; BOON, V.A. Quantitative determination of recombinant bovine somatotropin in commercial shrimp feed using a competitive enzyme-linked immunosorbent assay. Journal of Agriculture and Food Chemistry. v. 58, p.1429-33, 2010.

NEVES, J.P.; MIRANDA K.L.; TORTORELLA, R.D. Progresso científico em reprodução na primeira década do século XXI. Revista Brasileira de Zootécnica, v.39, supl.,p.414-421, 2010.

PELL, A.N.; TSANG, D.S.; HOWLETT, B.A.; HUYLER, M.T.; MESEROLE, V.K.; SAMUELS, W.A.; HARTNELL, $\quad$ G.F.; HINTZ, R.L. Effects of a prolonged- release formulation of Sometribove (n-methionyl bovine somatotropin) on Jersey cows. Jounal of Dairy Science, v.75, p.3416-3431, 1992.

PIVATO, I. Aspiração follicular em bovines - efeito do BST. Wokshop de reprodução animal, Pelotas, v.2, p.61-76, 2005.

RHOADS, R.P.; LA NOCE, A.J.; WHEELOCK, J.B.; BAUMGARD, L.H. Short communication: Alterations in expression of gluconeogenic genes during heat stress and exogenous bovine somatotropin administration. Journal of Dairy Science, v. 94, p.1917-21, 2011.

SILVA, J.C.B.; SANT'ANA, V.A.C.; OKABE, W.K.; DAMBIT, T.F.; MORENO, W.W.; RODRIGUES, E.; FERREIRA, M.A.; BASSO, A.C. Avaliação do uso da somatotropina recombinante bovina sobre a técnica de fertilização in vitro em ovelhas Santa Inês. Anais p.386. XXIV Reunião da Sociedade Brasileira de tecnologia de embriões (SBTE). Porto de Galinhas, 2010.

SPICER, L. J.; ECHTERNKAMP, S. E. The ovarian insulin and insulin-like growth factor system with an emphasis on domestic animals. Domestic Animals Endocrinology, v.12, p.223245, 1995. 
TATJANA, I. K.; ALM, H.; DENISENKO, V.; TUCHSCHERER, A.; TORNER, W.K.H. Effect of recombinat bovine somatotropin (rbST) on cytoplasmatic Maturation of bovine Oocytes and their development competence in vitro, Journal of Reproduction and Development, $v$. 53, p.2, 2007.

THATCHER, W.W.; MOREIRA, F.; SANTOS, J.E.; MATTOS, R.C.; LOPES, F.L.; PANCARCI, S.M.; RISCO, C.A. Effects of hormonal treatments on reproductive performance and embryo

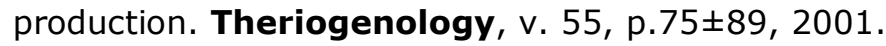

VARAGO, F.C.; MENDONÇA, L.F.; LAGARES, M.A. Produção in vitro de embriões: estado da arte e perspectivas de uma técnica em constante evolução. Revista Brasileira de Reprodução Animal, v.32, n.2, p.100-109, 2008. 